Check for updates

Kent

Cite this as: BMJ 2021;374:n2177 http://dx.doi.org/10.1136/bmj.n2177 Published: 06 September 2021

\section{Climate crisis: Over 200 health journals urge world leaders to tackle "catastrophic harm"}

\author{
Jacqui Wise
}

More than 200 health journals have called on governments to take emergency action to tackle the "catastrophic harm to health" from climate change.

A joint editorial says that while recent targets to reduce emissions and conserve biodiversity are welcome, they are not enough and need to be matched with credible short and longer term plans. ${ }^{1}$

The editorial was published simultaneously on 6 September in 233 international titles including The BMJ, the Lancet, the New England Journal of Medicine, the East African Medical Journal, the Chinese Science Bulletin, the National Medical Journal of India, and the Medical Journal of Australia. A full list of authors and signatories can be found here: https://bit.ly/3n1qzXB.

"As health professionals, we must do all we can to aid the transition to a sustainable, fairer, resilient, and healthier world," the editorial says. "We, as editors of health journals, call for governments and other leaders to act, marking 2021 as the year that the world finally changes course.”

The editorial is being published ahead of next week's UN General Assembly, one of the last international meetings taking place before the $\mathrm{COP} 26$ climate conference in Glasgow in November. It has been coordinated by the UK Health Alliance on Climate Change, a coalition of leading UK health bodies.

Fiona Godlee, editor in chief of The BMJ and one of the editorial's coauthors, said, "Health professionals have been on the front line of the covid-19 crisis, and they are united in warning that going above $1.5^{\circ} \mathrm{C}$ and allowing the continued destruction of nature will bring the next, far deadlier crisis.

"Wealthier nations must act faster and do more to support those countries already suffering under higher temperatures. 2021 has to be the year the world changes course-our health depends on it."

\section{Transforming economies}

Health professionals and health journals have been warning for decades about the severe and growing effects from climate change, including extreme temperatures, destructive weather events, and the degradation of essential ecosystems.

The impact of climate change disproportionately affects the most vulnerable people in society including children and elderly people, ethnic minorities, poorer communities, and people with underlying health conditions.

The editorial urges world leaders to transform societies and economies by supporting the redesign of transport systems, cities, the production and distribution of food, and markets for financial investments and health systems. This will need substantial investment but will have enormous positive benefits, it argues, including reduced air pollution, increased physical activity, and improved housing and diet.

Wealthier countries that have disproportionately created the environmental crisis must do more to support low and middle income countries in building cleaner, healthier, and more resilient societies, say the authors.

Eric Rubin, editor in chief of the New England Journal of Medicine, said, "The environment and health are inextricably intertwined. The changing climate is endangering us in many ways, including its critical impacts on health and healthcare delivery. As medical and public health practitioners, we have an obligation not only to anticipate new healthcare needs but also to be active participants in limiting the causes of the climate crisis."

Tedros Adhanom Ghebreyesus, director general of the World Health Organization, said, "The risks posed by climate change could dwarf those of any single disease. The IPCC [Intergovernmental Panel on Climate Change] report shows that every fraction of a degree hotter endangers our health and future. Similarly, every action taken to limit emissions and warming brings us closer to a healthier and safer future.”

Atwoli L, Baqui AH, Benfield T, etal. Call for emergency action to limit global temperature increases, restore biodiversity, and protect health. BMJ 2021;374:n1734. doi: 10.1136/bmj.n1734. https://www.bmj.com/content/374/bmj.n1734. 